\title{
Physicochemical studies and biological activity of mixed ligand complexes involving bivalent transition metals with a novel Schiff base and glycine as a representative amino acid
}

\author{
Abeer Taha Abedel Karim a and Ahmed Abdou El-Sherif a,b,* \\ a Department of Chemistry, Faculty of Science, Cairo University, Cairo, 12613 Egypt \\ b Department of Chemistry, Faculty of Arts and Science, Northern Borders University, Rafha, 156, Kingdom of Saudi Arabia \\ ${ }^{*}$ Corresponding author at: Department of Chemistry, Faculty of Science, Cairo University, Cairo, 12613 Egypt. \\ Tel.: +2.010.60160168. Fax: +2.02.35676562. E-mail address: aelsherif72@yahoo.com (A.A. El-Sherif).
}

\section{ARTICLE INFORMATION}

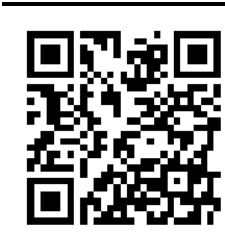

DOI: 10.5155 /eurjchem.5.2.328-333.1025

Received: 29 January 2014

Received in revised form: 16 February 2014

Accepted: 18 February 2014

Online: 30 June 2014

\section{KEYWORDS}

\section{Glycine}

Schiff base

Amino acid

Electronic spectra

Antibacterial activity

Mixed-ligand complexes

\section{Introduction}

Amino acids constitute the building blocks of proteins and act as indispensable chemical species for performing a huge number of biological functions, as exemplified by the role of enzymes [1]. Also, amino acids have special importance among the other chemical groups since they are the foundation stones of the living organisms. The environment around the metal center, as coordination geometry, number of coordinated ligands and their donor group, is the key factor for metalloprotein to carry out a specific physiological function [2]. About 20 zinc enzymes are known in which zinc is generally tetrahedrally four coordinate and bonded to hard donor atoms such as nitrogen or oxygen [3]. Manganese plays an important role in several biological redox-active systems $[4,5]$. The synthesis and reactivity of cobalt complexes of Schiff base ligands have always attracted the attention of inorganic chemists [6]. For instance, the cobalt complexes of tetradentate Schiff base ligands have been extensively used to mimic cobalamin $\left(\mathrm{B}_{12}\right)$ coenzymes [7-10], dioxygen carriers and oxygen activators $[11,12]$. The preparation of model complexes having similar spectroscopic features is perhaps the most important step to understand the structure and behavior of these biological systems. Schiff base metal complexes attract considerable interest and occupy an important role in the development of the chemistry of chelate systems $[12,13]$ due to the fact that especially these with $\mathrm{N}_{2} \mathrm{O}_{2}$ tetradentate ligands, such systems closely resemble metallo-proteins. Survey of the literature reveals an excellent work devoted to synthesis and characterization of many metal complexes of Schiff base [1417]. Additionally, it has been reported that Schiff bases and their first-row transition metal complexes can exhibit fungicidal, bactericidal, antiviral and antitumor activities in addition to their important roles in catalysis and organic synthesis [18-20]. Metal complexes of Schiff bases derived from substituted salicylaldehydes and various amines have been widely investigated because of their wide applicability [21-23] especially metal complexes of Schiff bases with heterocyclic compounds find applications as potential drugs [24]. Therefore, the synthesis of new Schiff bases and their complexes have been being a popular theme. The ternary complexes of the Schiff bases and amino acids with metal ions bear the importance of both Schiff bases and amino acids.

In continuation of our earlier work [25-30] and to widen the scope of investigation on the coordination behavior of Schiff base ligand and amino acids, we report here synthesis, characterization and biological activity of the ternary system including bivalent transition metal ions M(II), Schiff-base ligand 
Table 1. Analytical and physical data of the synthesized compounds.

\begin{tabular}{|c|c|c|c|c|c|c|}
\hline \multirow{2}{*}{ Compound } & \multirow{2}{*}{ Mw (g) } & \multirow{2}{*}{$\%$ Yield } & \multicolumn{4}{|c|}{ \% Found (Calcd.) } \\
\hline & & & C & $\mathbf{H}$ & $\mathbf{N}$ & $\mathbf{S}$ \\
\hline [Ni(ATS)(Gly)] (1) & 425.92 & 75 & $39.21(39.29)$ & $3.01(3.06)$ & $6.48(6.55)$ & $7.47(7.52)$ \\
\hline [Co(ATS)(Gly)]. $\mathrm{H}_{2} \mathrm{O}(2)$ & 444.93 & 77 & $37.71(37.75)$ & $2.42(2.47)$ & $6.22(6.29)$ & $7.16(7.19)$ \\
\hline$[\mathrm{Mn}(\mathrm{ATS})(\mathrm{Gly})] \cdot 2 \mathrm{H}_{2} \mathrm{O}(3)$ & 460.20 & 74 & $36.51(36.54)$ & $3.69(3.72)$ & $6.07(6.09)$ & $6.91(6.95)$ \\
\hline [Zn(ATS)(Gly)] (4) & 431.85 & 62 & $39.21(38.69)$ & $2.98(3.01)$ & $6.42(6.45)$ & $7.35(7.38)$ \\
\hline
\end{tabular}

(ATS) and glycine as a representative example of amino acids (Scheme 1). The complexes were characterized based on elemental analyses, IR, UV-Vis, magnetic moment and molar conductance measurements. The isolated metal chelates were screened for their antibacterial and antifungal activities and the results are reported and discussed.

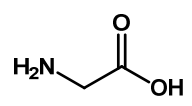

Glycine

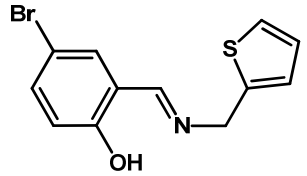

ATS-Schiff base
Scheme 1

\section{Experimental}

\subsection{Instrumentation}

The microchemical analysis of the separated solid chelates for $\mathrm{C}, \mathrm{H}$ and $\mathrm{N}$ were performed in the Microanalytical Center, Cairo University. The analyses were performed twice to check the accuracy of the analyses data. Infrared spectra were recorded on 8001-PC FTIR Shimadzu spectrophotometer using $\mathrm{KBr}$ pellets. The solid reflectance spectra were measured on a Shimadzu 3101 pc spectrophotometer. The molar conductance of the complexes was measured for $1.00 \times 10^{-3} \mathrm{M}$ DMSO solutions at $25 \pm 1{ }^{\circ} \mathrm{C}$ using a systronic conductivity bridge type 305 . The room temperature magnetic susceptibility measurements for the complexes were determined by the Gouy balance using $\mathrm{Hg}\left[\mathrm{Co}(\mathrm{SCN})_{4}\right]$ as a calibrant.

\subsection{Materials}

All chemicals used in this investigation were laboratory pure including $\mathrm{CoCl}_{2} \cdot 6 \mathrm{H}_{2} \mathrm{O}, \mathrm{NiCl}_{2} \cdot 6 \mathrm{H}_{2} \mathrm{O}, \mathrm{MnCl}_{2} \cdot 4 \mathrm{H}_{2} \mathrm{O}, \mathrm{ZnCl}_{2} \cdot 6 \mathrm{H}_{2} \mathrm{O}$, $\mathrm{C}_{2} \mathrm{H}_{5} \mathrm{OH}$, DMSO, 5-bromosalicylaldehyde, glycine, and 2-amino methylthiophene. All reagents were provided from Aldrich and Sigma chemicals companies.

\subsection{Preparation of Schiff base}

The Schiff base was prepared as reported in literature [31] by mixing an ethanolic solution $(20 \mathrm{~mL})$ of $2.01 \mathrm{~g}(0.01 \mathrm{~mol})$ of 5-bromosalicylaldehyde with $1.13 \mathrm{~g}(0.01 \mathrm{~mol})$ of 2 -amino methylthiophene in the same volume of ethanol. The mixture then refluxed with stirring for 1 hour. The precipitate was collected by filtration through buchner funnel, recrystal-lized from ethanol and dried at room temperature with $89 \%$ yield.

\subsection{Preparation of the solid complexes}

All complexes were prepared by refluxing an ethanolic solution of the Schiff base ligand ( $1 \mathrm{mmol}, 0.295 \mathrm{~g}$ ) and glycine ( $1 \mathrm{mmol}, 0.075 \mathrm{~g}$ Gly) with an ethanolic solution of metal salt (1 mmol, $\mathrm{CoCl}_{2} .6 \mathrm{H}_{2} \mathrm{O}, 0.2380 \mathrm{~g} ; \mathrm{NiCl}_{2} .6 \mathrm{H}_{2} \mathrm{O}, 0.2370 \mathrm{~g} ; \mathrm{MnCl}_{2} .4 \mathrm{H}_{2} \mathrm{O}$, $0.1979 \mathrm{~g}, \mathrm{ZnCl}_{2} .6 \mathrm{H}_{2} \mathrm{O}, 0.2429 \mathrm{~g}$ ) in the molar ratio $1: 1: 1$ (w:w:w). An equivalent amount of $\mathrm{NaHCO}_{3}$ was added to neutralize the released protons. The reaction mixtures were refluxed on a water bath for $4 \mathrm{~h}$ and allowed to cool to room temperature overnight. The precipitated complexes were then filtered off, washed with petroleum ether and dried overnight in a vacuum desiccator. The dried complexes were subjected to elemental and spectroscopic analysis.

\subsection{Biological activity}

The antimicrobial bioassay was performed according to protocols described previously using a modified Kirby-Bauer disc diffusion method [32-34]. The antimicrobial activities of metal complexes were studied against Gram (+) bacteria as (Staphylococcus epidermidis ATCC 12228 and Bacillus cereus ATCC 10876); Gram (-) bacteria as (Pseudomonas aeuroginosa ATCC 10145 and Escherichia coli ATCC 35939) and fungi as Aspergillus fumigatus ATCC 46645 and Aspergillus niger ATCC 9029. Standard discs of Ciprofloxacin (antibacterial agent), Ketoconazole (antifungal agent) served as positive controls for antimicrobial activity but filter discs impregnated with $10 \mu \mathrm{L}$ of solvent (DMSO) were used as a negative control.

\section{Results and discussion}

The condensation of 5-bromosalicylaldehyde with 2-amino methylthiophene in boiling ethanol yields a Schiff base compound (ATS) as reported in literature [31]. The elemental analyses for the interaction of Schiff base ligand and glycine amino acid with metal (II) chloride in EtOH agree well with a 1:1:1 M(II):ATS:Gly stoichiometry for all the complexes. The results of elemental analysis (C, H, N and S), along with molecular formulae and percent yield of the complexes are presented in Table 1. The complexes are air stable, insoluble in the most organic solvents and water but freely soluble in DMF and DMSO. The complexes have higher melting points than their corresponding ligands indicating that they are thermally stable. This could be attributed to the formation of chelate rings.

\subsection{IR Spectra and mode of bonding}

The results of IR measurements were listed in Table 2 with assignments for the most of the major peaks. The IR spectrum of the free Schiff base ligand (ATS) reveals a band at $3458 \mathrm{~cm}^{-1}$ due to $v(\mathrm{OH})$. This band is absent in the spectra of metal(II) complexes, indicating coordination through the deprotonated phenolic $\mathrm{OH}$ group [35]. Moreover, it was evidenced by the shift in position of $v_{\text {co }}$ (aromatic carbon and phenolic oxygen) at $1319 \mathrm{~cm}^{-1}$ [36] to the lower frequency region in the spectra of complexes [37]. However, the strong band observed at 1675 $\mathrm{cm}^{-1}$ in the free ATS ligand due to azomehtine group vibration is shifted towards lower frequencies in the complexes by (28$37 \mathrm{~cm}^{-1}$ ), suggesting that azomethine group is involved in coordination $[38,39]$.

In the free Schiff base ligand, the sharp band observed at $825 \mathrm{~cm}^{-1}$ due to $v(\mathrm{C}-\mathrm{S}-\mathrm{C}$ ) stretching frequency of thiophene ring remained unchanged in all complexes confirming the noninvolvement of the thiophene sulfur in complex formation [40].

The appearance of new bands in the low frequency ranges at 501-525 and 445-412 $\mathrm{cm}^{-1}$ due to $v(\mathrm{M}-\mathrm{O})$ and $v(\mathrm{M}-\mathrm{N})$ vibrations [41] respectively, support the participation of the 
Table 2. Tentative assignment of the important infrared bands of the synthesized complexes.

\begin{tabular}{|c|c|c|c|c|c|c|c|c|c|c|c|}
\hline \multirow[t]{2}{*}{ Compound } & \multicolumn{11}{|c|}{$v\left(\mathrm{~cm}^{-1}\right)$} \\
\hline & Уон & $V_{(C=N)}$ & $\begin{array}{l}\delta_{\mathrm{NH} 3+} \\
\text { (Free AA) }\end{array}$ & $\begin{array}{l}V_{(\mathrm{C}-0)} \\
\text { phenolic }\end{array}$ & $\begin{array}{l}V_{\text {asym }} \\
(\text { Coo) }\end{array}$ & $\begin{array}{l}V_{\text {sym }} \\
(\text { Coo) }\end{array}$ & $\Delta v$ & $\begin{array}{l}\mathbf{V}_{\mathrm{NH} 2} \\
\text { (Coord. AA) }\end{array}$ & $v_{(C-S)}$ & $\mathbf{v}_{M-N}$ & $\mathbf{v}_{\mathrm{M}-\mathrm{O}}$ \\
\hline$\overline{\text { ATS }}$ & 3458 & 1675 & - & 1319 & - & - & - & - & 825 & - & - \\
\hline Gly & - & - & 1585 & - & 1608 & 1412 & & - & - & - & - \\
\hline [Ni(ATS)(Gly)] (1) & - & 1638 & - & 1282 & 1590 & 1379 & 211 & $3420 ; 3190$ & 824 & 445 & 525 \\
\hline$\left[\mathrm{Co}(\right.$ ATS $)$ (Gly)]. $\mathrm{H}_{2} \mathrm{O}(2)$ & 3518 & 1635 & - & 1280 & 1591 & 1382 & 209 & $3410 ; 3202$ & 826 & 428 & 512 \\
\hline$[\mathrm{Mn}(\mathrm{ATS})(\mathrm{Gly})] \cdot 2 \mathrm{H}_{2} \mathrm{O}(3)$ & 3530 & 1640 & - & 1285 & 1589 & 1381 & 208 & $3415 ; 3198$ & 825 & 412 & 505 \\
\hline [Zn(ATS)(Gly)] (4) & - & 1647 & - & 1270 & 1587 & 1380 & 207 & $3414 ; 3200$ & 826 & 418 & 501 \\
\hline
\end{tabular}

ATS: 2-Aminomethylthiophenyl-4-bromosalicylaldehyde; Gly: Glycine.

Table 3. Molar conductance, magnetic moment, electronic spectra and electron spin resonance data of [M(ATS)(Gly)] complexes.

\begin{tabular}{|c|c|c|c|c|c|c|}
\hline \multirow[t]{2}{*}{ Compound } & \multirow[t]{2}{*}{$\Lambda_{\mathrm{M}}{ }^{\mathrm{a}}$} & \multirow{2}{*}{$M_{\text {eff. }}$ (B.M.) } & \multicolumn{3}{|c|}{$\lambda_{\max }\left(\mathrm{cm}^{-1}\right)$} & \multirow[t]{2}{*}{ Assignment } \\
\hline & & & $\mathbf{n} \rightarrow \pi^{*}$ & $\pi \rightarrow \pi^{*}$ & $d-d$ transition & \\
\hline$\overline{\text { ATS }}$ & - & - & 28409 & 40816 & - & \\
\hline$\overline{\text { [Ni(ATS)(Gly)] (1) }}$ & 13.8 & Diamag. & 32294 & 43450 & $\begin{array}{l}14122 \\
24165\end{array}$ & $\begin{array}{l}{ }^{1} \mathrm{~A}_{1 \mathrm{~g}} \rightarrow{ }^{1} \mathrm{~B}_{2 \mathrm{~g}} \\
{ }^{1} \mathrm{~A}_{1 \mathrm{~g}} \rightarrow{ }^{1} \mathrm{~B}_{1 \mathrm{~g}}\end{array}$ \\
\hline$[\mathrm{Co}(\mathrm{ATS})(\mathrm{Gly})] \cdot \mathrm{H}_{2} \mathrm{O}(2)$ & 12.2 & 4.11 & 34524 & 43780 & 15826 & ${ }^{4} \mathrm{~A}_{2}(\mathrm{~F}) \rightarrow{ }^{4 \mathrm{~T}} \mathrm{~T}_{1}(\mathrm{P})$ \\
\hline$[\mathrm{Mn}(\mathrm{ATS})(\mathrm{Gly})] \cdot 2 \mathrm{H}_{2} \mathrm{O}(3)$ & 11.9 & 5.62 & 36712 & 44230 & $\begin{array}{l}12210 \\
17627 \\
19190\end{array}$ & $\begin{array}{l}{ }^{6} \mathrm{~A}_{1} \rightarrow{ }^{4} \mathrm{~T}_{1} \\
{ }^{6} \mathrm{~A}_{1} \rightarrow{ }^{4} \mathrm{~T}_{2}(\mathrm{G}) \\
{ }^{6} \mathrm{~A}_{1} \rightarrow{ }^{4} \mathrm{E}\end{array}$ \\
\hline [Zn(ATS)(Gly)] (4) & 12.8 & Diamag. & 35860 & 44010 & - & - \\
\hline
\end{tabular}

a Molar conductance measured for $1 \times 10^{-3} \mathrm{M}$ DMSO solution, $\Omega^{-1} \mathrm{~cm}^{2} \mathrm{~mol}^{-1}$; Gly= Glycine and ATS = 2-aminomethylthiophenyl-4-bromosalicylaldehyde.

nitrogen atom of the azomethine group and oxygen of the $\mathrm{OH}$ group of the Schiff-base ligand in the complexation with metal(II) ion [41]. The amino acid was coordinated as bidentate and bound to the central metal ion through the carboxylate and the amino groups. The $\delta \mathrm{NH}_{3}{ }^{+}$band, which is characteristic of zwitter ion, disappears in the spectra of complexes. This indicates that the $\mathrm{NH}_{2}$ group must be involved in coordination. This is supported by the appearance of stretching vibration of amino group as split bands in the regions 3424-3410 and 3202$3190 \mathrm{~cm}^{-1}$ [42] assigned for the coordinated amino group [42]. One particularly interesting aspect to be analyzed in complexes of this type is the displacement of the characteristic carboxylic bands after coordination. This peculiar aspect has been summarized in Table 2. The "free" amino acid exists as zwitter ion in the crystalline state; thus, one expects two stretching vibrations for the $\mathrm{COO}^{-}$moiety present in these systems, namely $v_{s}\left(\mathrm{COO}^{-}\right)$and $v_{\text {as }}\left(\mathrm{COO}^{-}\right)$. The first one is usually of medium intensity in the IR spectrum, whereas the second is strong and broad. The bands in the regions 1608 and 1412 $\mathrm{cm}^{-1}$, due to $v_{\text {asym }}\left(\mathrm{COO}^{-}\right)$and $\nu_{\text {sym }}$ (COO-) of glycine amino acid appear in the complexes at 1587-1591 and 1379-1382 $\mathrm{cm}^{-1}$. The frequency difference between asymmetric and symmetric vibration of carboxylate is found to be $>200 \mathrm{~cm}^{-1}$ reflecting the monodentate coordination of carboxylate group of amino acid with the metal ion in the synthesized complexes [43-45]. The shift of these two bands suggests the involvement of the carboxylic group of the amino acids in the complex formation.

This conclusion is supported further by the absence of the band at $1705 \mathrm{~cm}^{-1}$ in the IR spectra of the metal complexes, which is due to the $v_{\text {asym }}(\mathrm{C}=0)$ mode associated with the bidentate coordinated $-\mathrm{COOH}$ groups of the amino acid ligand. Hence, the amino acid moiety is chelated to the metal ion forming five-membered chelate ring. The $\mathrm{OH}$ stretching frequency appears in the spectra of M(II) complexes around 3518-3530 $\mathrm{cm}^{-1}$ is attributed the presence of water of hydration. Also, according to Stefov et al. [46], coordinated water should exhibit frequencies at 825,575 and $500 \mathrm{~cm}^{-1}$. The absence of spectral bands in these regions in the spectra of $\mathrm{M}$ (II) complexes indicates that the water molecules in these complexes are not coordinated but is present as lattice water.

As a general conclusion, the Schiff base participated in bonding to metal(II) ion as monobasic bidentate ( $\mathrm{N}$ and $\mathrm{O}$ donor) ligand and glycine amino acid also as monobasic bidentate ligand with a total of four coordination sites around the M(II) ion whose charge is neutralized by the deprotonation of the Schiff base phenolic $\mathrm{OH}$ and the amino acid $\mathrm{COOH}$. The nonelectrolytic nature of the complexes was evidenced from the low values of the molar conductance of the complexes measured in DMSO [47,48] (Table 3).

\subsection{Conductivity measurements}

The chelates were dissolved in DMSO and the molar conductivities of $1 \times 10^{-3} \mathrm{M}$ of their solutions at $25 \pm 1{ }^{\circ} \mathrm{C}$ were measured. As seen from Table 3, the molar conductivity values for $\mathrm{M}(\mathrm{II})$-chelates are $11.9-13.8 \Omega^{-1} \mathrm{~cm}^{2} \mathrm{~mol}^{-1}$ indicating nonelectrolytic nature of the complexes.

\subsection{Electronic spectra and magnetic moment measurements}

As the result of failure to obtain a single crystal for X-ray analyses to confirm the geometric structure for these complexes, solid reflectance spectra and magnetic moment measurements are used for this purpose. The solid reflectance spectra of metal complexes show different bands at different wavelengths, each one is corresponding to certain transition which suggests the geometry of the complex compounds. The complexes show two bands in the 43450-44230 and 32294$36712 \mathrm{~cm}^{-1}$ ranges which are assigned to intra-ligand transition [49].

The electronic spectrum of the Ni(II) complex (1) showed two bands for complex (1). The two bands in the spectrum of the nickel(II) complex observed at 14,122 and $24,165 \mathrm{~cm}^{-1}$ which may be assigned to the ${ }^{1} \mathrm{~A}_{1 \mathrm{~g}} \rightarrow{ }^{1} \mathrm{~B}_{2 \mathrm{~g}}$ and ${ }^{1} \mathrm{~A}_{1 \mathrm{~g}} \rightarrow{ }^{1} \mathrm{~B}_{1 \mathrm{~g}}$ transitions, respectively for a square-planar geometry around $\mathrm{Ni}(\mathrm{II})$. The assumed square planar geometry for this complex is confirmed from the value of its room temperature magnetic moment of zero [50].

The electronic spectrum of the mononuclear Co(II) complex (2) showed a strong band at $15826 \mathrm{~cm}^{-1}$ which is assigned to the ${ }^{4} \mathrm{~A}_{2}(\mathrm{~F}) \rightarrow{ }^{4} \mathrm{~T}_{1}(\mathrm{P})$ transition, suggesting tetrahedral geometry around $\operatorname{Co}(\mathrm{II})$ ion as reported in literature [51,52]. The measured magnetic moment of Co(II) complex (2) is given in Table 3. The theory of magnetic susceptibility of Co(II) ion was given by Schlapp and Penney [53] and the best summary of results on the magnetism behavior of cobalt(II) compounds is that of Figgis and Nyhlom [54].

The observed values of magnetic moments for cobalt (II) complexes are generally diagnostic of the coordination geometry about the metal ion. The effective magnetic moment value ( $\mu_{\text {eff }}$ ) for the mononuclear Co(II) complex (2) is 4.11 B.M. (Table 3), which is lower than the expected range for tetrahedral cobalt(II) complexes (4.2-4.7 B.M.) according to the literature cited values $[55,56]$. 
Table 4. Antibacterial and antifungal activities of mixed-ligand complexes.

\begin{tabular}{|c|c|c|c|c|c|c|}
\hline \multirow[t]{4}{*}{ Compounds } & \multicolumn{6}{|c|}{ Diameter of inhibition zone (in $\mathrm{mm}$ ) a } \\
\hline & \multicolumn{4}{|l|}{ Bacteria } & \multirow{2}{*}{\multicolumn{2}{|c|}{ Fungi }} \\
\hline & \multicolumn{2}{|l|}{ Gr (-) } & \multicolumn{2}{|l|}{ Gr (+) } & & \\
\hline & $\begin{array}{l}\text { Pseudomonas } \\
\text { aeuroginosa } \\
\text { ATCC } 9027\end{array}$ & $\begin{array}{l}\text { Escherichia } \\
\text { coli } \\
\text { ATCC } 35939\end{array}$ & $\begin{array}{l}\text { Bacillus cereus } \\
\text { ATCC } 10876\end{array}$ & $\begin{array}{l}\text { Staphylococcus } \\
\text { epidermidis } \\
\text { ATCC } 12228\end{array}$ & $\begin{array}{l}\text { Aspergillus niger } \\
\text { ATCC } 9029\end{array}$ & $\begin{array}{l}\text { Aspergillus } \\
\text { fumigatus } \\
\text { ATCC } 46645\end{array}$ \\
\hline Concentration $(\mu \mathrm{g} / \mathrm{mL})$ & 100 & 100 & 100 & 100 & 100 & 100 \\
\hline [Ni(ATS)(Gly)] (1) & $13.8 \pm 0.11$ & $11.5 \pm 0.31$ & $19.3 \pm 0.17$ & $20.5 \pm 0.54$ & $23.6 \pm 0.15$ & $23.2 \pm 0.22$ \\
\hline$[\mathrm{Co}(\mathrm{ATS})(\mathrm{Gly})] \cdot \mathrm{H}_{2} \mathrm{O}(2)$ & $12.7 \pm 0.49$ & NA ${ }^{b}$ & $18.4 \pm 0.13$ & $19.1 \pm 0.75$ & $19.6 \pm 0.23$ & $20.2 \pm 0.32$ \\
\hline$[\mathrm{Mn}(\mathrm{ATS})(\mathrm{Gly})] \cdot 2 \mathrm{H}_{2} \mathrm{O}(\mathbf{3})$ & $11.3 \pm 0.63$ & $\mathrm{NA}^{\mathrm{b}}$ & $15.1 \pm 0.47$ & $16.3 \pm 0.34$ & $16.7 \pm 0.52$ & $18.3 \pm 0.12$ \\
\hline [Zn(ATS)(Gly)] (4) & $19.9 \pm 0.24$ & $17.2 \pm 0.15$ & $23.5 \pm 0.21$ & $27.9 \pm 0.67$ & $25.7 \pm 0.35$ & $26.3 \pm 0.44$ \\
\hline Standard c & $22 \pm 0.15$ & $27 \pm 0.18$ & $24 \pm 0.28$ & $28 \pm 0.14$ & $28 \pm 0.12$ & $30 \pm 0.38$ \\
\hline
\end{tabular}

a Mean zone of inhibition in mm \pm standard deviation beyond well diameter (6 mm) produced on a range of environmental and clinically pathogenic microorganisms.

bNA: not detected.

c Ciprofloxacin is used as standard for antibacterial activity and Ketoconazole is used as standard for antifungal activity.

The lower magnetic moment value of the [Co(ATS)(Gly)] complex would point to a not purely tetrahedral geometry of cobalt(II) and a tendency to be distorted [57].

The magnetic moment value of Mn(II) complex under study is found to be 5.62 B.M. The solid reflectance data of $\mathrm{Mn}(\mathrm{II})$ complex show the observed bands at 12210, 17627 and 19190 $\mathrm{cm}^{-1}$ attributable to ${ }^{6} \mathrm{~A}_{1} \rightarrow{ }^{4} \mathrm{~T}_{1},{ }^{6} \mathrm{~A}_{1} \rightarrow{ }^{4} \mathrm{~T}_{2}(\mathrm{G})$ and ${ }^{6} \mathrm{~A}_{1} \rightarrow{ }^{4} \mathrm{E}$ transitions, respectively suggest a tetrahedral stereochemistry for this complex [58].

Due to the $d^{10}$ electronic configuration of the metallic $\mathrm{Zn}(\mathrm{II})$ ion, electronic spectra of the $\mathrm{Zn}$ (II)-complex do not allow suggestion concerning its stereochemistry. On the basis of the analytical data, molar conductance, diamagnetic nature and the number of donor atoms of the ligands, a tetrahedral geometry is presumed for the zinc(II) complex and in analogy with those described for $\mathrm{Zn}$ (II) complexes containing $\mathrm{N}-\mathrm{O}$ donors [59,60]. This is in accordance with the preference of $\mathrm{Zn}$ (II) for tetrahedral coordination [61].

\subsection{Mass spectra}

Appearance of final peak at $\mathrm{m} / z 295\left(\mathrm{C}_{12} \mathrm{H}_{10} \mathrm{NOSBr}\right.$, calculated atomic mass $295 \mathrm{amu}$ ) confirm the proposed formula of ATS-Schiff base and other peaks at 200, 184, 171, 156, 143 and 63 amu may be due to fragmentation of ATS molecule as a result of the rupture of different bonds inside the molecule [62]. The mass spectra of the complexes [Ni(ATS)(Gly)], [Co(ATS)(Gly)]. $\mathrm{H}_{2} \mathrm{O},[\mathrm{Mn}(\mathrm{ATS})(\mathrm{Gly})] \cdot 2 \mathrm{H}_{2} \mathrm{O}$ and [Zn(ATS)(Gly)] are reported and their molecular ion peaks are in agreement with their assigned formulae. The mass spectrum of [Ni(ATS)(Gly)] showed a molecular ion peak $\left(\mathrm{M}^{+}\right)$at $\mathrm{m} / z$ 425.92 that is equivalent to its molecular weight having the formula $\mathrm{NiC}_{14} \mathrm{H}_{13} \mathrm{~N}_{2} \mathrm{SO}_{3} \mathrm{Br}$ and suggesting the monomeric nature of the complex. Thus, the mass spectral data results along with elemental analyses agree with the formation of [Ni(ATS)(Gly)] complex of 1:1:1 stoichiometry. Additionally, the mass spectrum of [Co(ATS)(Gly)]. $\mathrm{H}_{2} \mathrm{O}$ showed also fragmentation patterns corresponding to the successive degradation of the complex. The peaks at $\mathrm{m} / z \quad 427.93$ and 353.93 correspond to $[\mathrm{Co}(\mathrm{ATS})(\mathrm{Gly})]^{+}$and $[\mathrm{Co}(\mathrm{ATS})]^{+}$ fragments, respectively. The mass spectra of [Mn(ATS)(Gly)].2 $\mathrm{H}_{2} \mathrm{O}$ and [Zn(ATS)(Gly)] showed signals at $\mathrm{m} / \mathrm{z} 459.90$ (Calcd. 460.20) and 431.61 (Calcd. 431.85). The fragmentation pattern is similar to [Co(ATS)(Gly)]. $\mathrm{H}_{2} \mathrm{O}$ complex in stepwise ligand loss.

\subsection{Structure of the complexes}

It is concluded that from elemental analysis, IR, conductance, electronic spectra, magnetic and conductance measurements, the ATS-Schiff base behaves as a monobasic bidentate ligand coordinated to the M(II) ion through the deprotonated hydroxo group and the azomethine-N atom while amino acid acts as a monobasic bidentate ligand coordinated through the amino and carboxylate groups (Scheme 2). On the basis of the elemental analysis and spectral data square planar geometry is suggested for $\mathrm{Ni}(\mathrm{II})$ complex in addition to tetrahedral geometry for $\mathrm{Co}(\mathrm{II}), \mathrm{Mn}(\mathrm{II})$, and $\mathrm{Zn}(\mathrm{II})$ complexes.
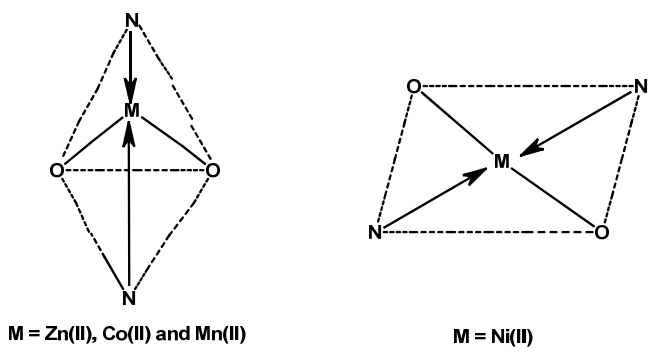

$M=N i(I I)$

The general proposed structure for M-ATS-Gly complexes (Water of hydration is excluded for simplicity).

Scheme 2

\subsection{Biological activity}

\subsubsection{Antibacterial activity}

To assess the biological potential of the synthesized compounds, the metal complexes were tested against different species of bacteria. In testing the antimicrobial activity of these compounds, we used more than one test organism to increase the chance of detecting antibiotic principles in tested materials. The organisms used in the present investigations included two Gram positive (Staphylococcus epidermidis and Bacillus cereus) and two Gram negative (Escherichia coli and Pseudomonas aeruginosa). The disc diffusion method was used to evaluate the antibacterial activity of the synthesized mixed ligand complexes. The medium used for growing the culture was nutrient agar. The results of the antimicrobial activities of the synthesized compounds are recorded in Table 4 . The biological activity of complexes may be arising from the hydroxyl groups which may play an important role in the antibacterial activity [63]. The mode of action of the compounds may involve formation of a hydrogen bond through the azomethine group $(>\mathrm{C}=\mathrm{N}-$ ) with the active centers of various cellular constituents, resulting in interference with normal cellular processes [64]. It has been suggested that the ligands with nitrogen and oxygen donor systems inhibit enzyme activity, since the enzymes which require these groups of their activity appear to be especially more susceptible to deactivation by metal ions on coordination. Moreover, coordination reduces the polarity of the metal ion mainly because of the partial sharing of its positive charge with the donor groups [65] within the chelate ring system formed during coordination. This process, in turn, increases the lipophilic nature of the central metal atom, which favors its permeation more efficiently through the lipid layer of 
the microorganism [66], thus destroying them more aggressively. The antibacterial activity can be ordered as $[\mathrm{Zn}(\mathrm{ATS})($ Gly) $]>[\mathrm{Ni}(\mathrm{ATS})($ Gly) $]>[\mathrm{Co}(\mathrm{ATS})($ Gly $)]>$ [Mn(ATS)(Gly)] (Figure 1), suggesting that the lipophilic behaviour increases in the same order.

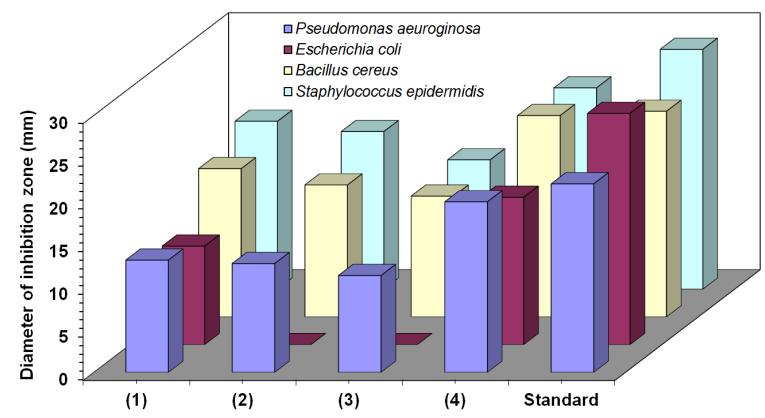

Figure 1. Antibacterial activity of M(II)-complexes towards different types of bacterial strains.

\subsubsection{Antifungal activity}

The antifungal activities of the synthesized complexes were tested against Aspergillus niger and Aspergillus fumigatus test organisms in-vitro using disc-diffusion method. The Ketoconazole was used as standards drug. The susceptibility of the selected strains of fungi towards the synthesized complexes was judged by measuring the diameter of the formed zone of inhibition. The results are given in Table 4. Metal ions are adsorbed on the cell walls of the microorganisms, disturbing the respiration processes of the cells and thus blocking the protein synthesis that is required for further growth of the organisms. Hence, metal ions are essential for the growthinhibitory effects. According to Overtone's concept of cell permeability, the lipid membrane that surrounds the cell favors the passage of only lipid-soluble materials, so lipophilicity is an important factor controlling the antifungal activity. Upon chelation, the polarity of the metal ion will be reduced due to the overlap of the ligand orbitals and partial sharing of the positive charge of the metal ion with donor groups. This increased lipophilicity facilitates the penetration of the complexes into lipid membranes, further restricting proliferation of the microorganisms. In general, the [Mn(ATS)(Gly)] compound was found to be less effective against the selected fugal strains and [Zn(ATS)(Gly)] complex is the most active one among the synthesized bivalent metal(II)complexes. Thus, the antifungal activity can be ordered as $[$ Zn(ATS)(Gly) $]>[\mathrm{Ni}($ ATS $)$ (Gly) $]>[\mathrm{Co}($ ATS $)($ Gly $)]>$ [Mn(ATS)(Gly)] (Figure 2).

\section{Conclusions}

The present paper reports on the synthesis, characterization and electronic absorption spectra of mixedligand complexes of M(II) with Schiff base ligand (ATS) and glycine as a representative example of amino acids. The synthetic procedure in this work resulted in the formation of complexes in the molar ratio (1:1:1) (M(II):ATS:Gly). The newly synthesized Schiff base participated in bonding to metal as monobasic bidentate ligand through the azomethine nitrogen and phenolic oxygen atom via deprotonation forming stable six membered heterocyclic ring. The glycine amino acid also acts as monobasic bidentate ligand via amino and ionized carboxylate groups. Thus, the charge of metal ion was neutralized by the deprotonation of the Schiff base phenolic-OH group and the amino acid carboxylate group with a total of four coordination sites around the metal. From conductance measurements all complexes are non-electrolytes. The antibacterial and antifungal activities of the synthesized compounds were investigated. Coordination to metal(II) resulted in complexes with increased antimicrobial activity comparable activity to the standard drug antibiotics. The increased use of antibacterial and antifungal agents in recent years has resulted in the development of resistance to these drugs. The important clinical implication of resistance has led to renewed interest in the development of novel antibacterial and antifungal agents. Hence the studied compounds could constitute alternatives as drug candidates for the treatment of microbial diseases.

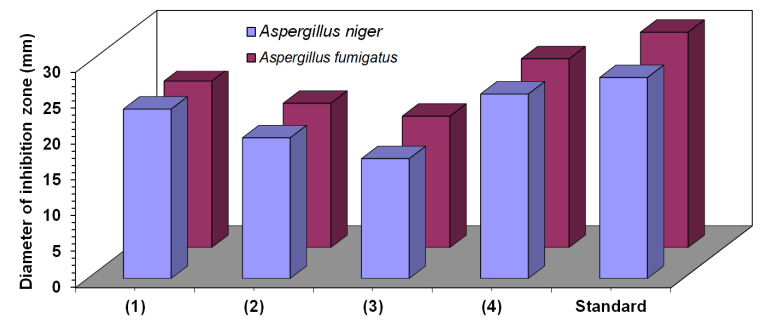

Figure 2. Antifungal activity of M(II)-complexes towards different types of fungal strains.

\section{References}

[1]. Zimmermann, K. H. An Introduction to Protein Informatics, Kluwer Academic Publishers, London, 2003.

[2]. Klement, R.; Stock, F.; Elias, H.; Paulus, H.; Pelikan, P.; Valko, M.; Mazur, M. Polyhedron 1999, 18, 3617-3628.

[3]. Marchettic, F.; Pettinari, C.; Pettinari, R.; Cingolani, A.; Leanesi, D.; Lorenotti, A. Polyhedron 1999, 18, 3041-3050.

[4]. Zhang, C.; Sun, J.; Kong, X.; Zhao, C. J. Coord. Chem. 2000, 50, 353-361.

[5]. Ramappa, P. G. J. Indian Chem. Soc. 1999, 76, 235-238.

[6]. Amirnasr, M.; Schenk, K. J.; Gorji, A.; Vafazadeh, R. Polyhedron 2001, 20, 695-702.

[7]. Cmi, R.; Moore, S. J.; Marzilli, L. G. Inorg. Chem. 1998, 37, 6890-6897.

[8]. Polson, S. M.; Cini, R.; Pifferi, C.; Marzilli, L. G. Inorg. Chem. 1997, 36 314-322.

[9]. Hirota, S.; Kosugi, E.; Marzilli, L. G.; Yamauchi, O. Inorg. Chim. Acta 1998, 275, 90-97.

[10]. Martell, A. E.; Sawyer, D. T. Oxygen Complexes and Oxygen Activation by Transition Metals, Plenum Press, New York, 1988.

[11]. Henson, N. J.; Hay, P. J.; Redondo, A. Inorg. Chem. 1999, 38, 1618-1626.

[12]. Gurian, P. L.; Cheatham, L. K.; Ziller, J. W.; Barron, A. R. J. Chem. Soc. Dalton Trans. 1991, 1449-1456.

[13]. Labisbal, E.; Garcia-Vazquez, J. A.; Romero, J.; Picos, S.; Sousa, A Polyhedron 1995, 14, 663-670.

[14]. Zolezzi, S.; Decinti, A.; Spodine, E. Polyhedron 1999, 18, 897-904.

[15]. Pasini, A.; Demartin, F.; Piovesana, O.; Chiari, B.; Cinti, A.; Crispu, O. J. Chem. Soc. Dalton Trans. 2000, 3467-3472.

[16]. Sangeetha, N. R.; Pal, S. Polyhedron 2000, 19, 1593-1600.

[17]. Jouad, E. l.; Riou, A.; Allain, M.; Khan, M. A.; Bouet, G. M. Polyhedron 2001, 20, 67-74.

[18]. Nath, M.; Pokharia, S.; Yadav, R. Coord. Chem. Rev. 2001, 215, 99-107.

[19]. Sharghi, H.; Nasser, M. A. Bull. Chem. Soc. (Jpn) 2003, 76, 137-142.

[20]. Gao, W. T.; Zheng, Z. Molecules 2001, 7, 511-516.

[21]. Canpolat, E.; Kaya, M. J. Coord. Chem. 2004, 57, 127-134.

[22]. Fan, Y.; Bi, C.; Li, J. Synth. React. Inorg. Met. Org. Chem. 2003, 33, 137145 .

[23]. Canpolat, E.; Kaya, M.; Yazici, A. Spectrosc. Lett. 2005, 38, 35-45.

[24]. Konstantinivi, S. S.; Radovanovi, B. C.; Caki, Z.; Vasic, V. J. Ser. Chem. Soc. 2003, 68, 641-648.

[25]. Jeragh, B.; Al-Wahaib, D.; El-Sherif, A. A.; El-Dissouky, A. J. Chem. Eng. Data 2007, 52, 1609-1614.

[26]. El-Sherif, A. A. J. Solution Chem. 2006, 35, 1287-1301.

[27]. Mohamed, M. M. A.; El-Sherif, A. A. J. Solution Chem. 2010, 39, 639653.

[28]. El-Sherif, A. A.; Shoukry, M. M. J. Coord. Chem. 2005, 58(16), 14011415.

[29]. El-Sherif, A. A.; Shoukry, M. M. Spectrochim. Acta A 2007, 66, 691-700.

[30]. El-Sherif, A. A.; Shoukry, M. M. Inorg. Chim. Acta 2007, 360, 473-487.

[31]. El-Sherif, A. A.; Eldebss, T. M. Spectrochim. Acta A 2011, 79, 18031814.

[32]. Pfaller, M. A.; Burmeister, L.; Bartlett, M. A.; Rinaldi, M. G. J. Clin. Microbiol. 1988, 26, 1437-1441.

[33]. Liebowitz, L. D.; Ashbee, H. R.; Evans, E. G. V.; Chong, Y.; Mallatova, N.; Zaidi, M.; Gibbs, D. Microbiol. Infet. Dis. 2001, 24, 27-33.

[34]. Bauer, A. W.; Kirby, W. M.; Sherris, C.; Turck, M. J. Am. Clin. Path. 1996, 45, 493-499.

[35]. El-Sherif, A. A.; Shehata, M. R.; Shoukry, M. M.; Barakat, M. H. J. 
Spectrochim. Acta A 2012, 96, 889-897.

[36]. Kulkarni, A.; Patil, S. A.; Badami, P. S. Eur. J. Med. Chem. 2009, 44, 2904-2912.

[37]. Sarkar, S.; Dey, K. Spectrochim. Acta A 2005, 62, 383-393.

[38]. West, D. X.; Nassar, A. A. Trans. Met. Chem. 1998, 23, 321-326.

[39]. Bagihalli, G. B.; Avaji, P. G.; Patil, S. A.; Badami, P. S. Eur. J. Med. Chem. 2008, 43, 2639-2649.

[40]. Gronowitz, S.; Katritsky, A. R.; Reavill, R. E. J. Am. Chem. Soc. 1964, 86, 3881-3882.

[41]. El-Sherif, A. A.; Aljahdali, M. S.; Hilal, R. H. Eur. J. Chem. 2013, 4(4), 370-378.

[42]. Nakamoto, K.; Infrared Raman Spectra of Inorganic and Coordination Compounds, Third ed., John Wiley and Sons, New York, 1992.

[43]. Decon, G. B.; Philips, R. J. Coord. Rev. 1980, 33, 227-250.

[44]. Aljahdali, M. S. Spectrochim. Acta A 2013, 112, 364-376

[45]. El-Sherif, A. A.; Shoukry, M. M.; Abobakr, L. O. J. Spectrochim. Acta A 2013, 112, 290-300

[46]. Stefov, V.; Petrusevski, V. M.; Soptrajanov, B. J. Mol. Struct. 1993, 293, 97-100.

[47]. Aljahdali, M.; El-Sherif, A. A. Inorg. Chim. Acta 2013, 407, 58-68.

[48]. Aljahdali, M. S. Eur. J. Chem. 2013, 4(4), 434-443.

[49]. El-Sherif, A. A.; Shoukry, M. M.; Abd-Elgawad, M. M. A. J. Spectrochim. Acta A 2012, 98, 307-321.

[50]. Dingle, R. Inorg. Chem. 1971, 10, 1141-1144.

[51]. Shrivastav, A.; Kishore, N.; Singh, S. M. Biometals 2003, 16(2), 311320.

[52]. Khalil, S. M. E.; El-Shafiy, H. F. O. Synth. React. Inorg. Met. Org. Chem. 2000, 30, 1817-1826.

[53]. Schlapp, R.; Penney, W. G. Phys. Rev. 1932, 42, 666-686.

[54]. Figgis, B. N.; Nyhlom, R. S. J. Chem. Soc. 1958, 4190-4200.

[55]. Salib, K. A. R.; Saleh, A. A.; Abu El-Wafa, S.; El-Shafiy, H. F. O. J. Coord. Chem. 2003, 56(4), 283-291.

[56]. El-Sherif, A. A. J. Solution Chem. 2010, 39, 1562-1581.

[57]. Bailar, J. C.; Emeleus, H. J.; Nyhlom, R.; Trotmon-Dickenson, A. F., Comprehensive Inorg. Chem. , Pergamon Press, New York 1975, 3, pp. 1048, 1049, 1089, 1093, 1153.

[58]. Mishra, R. C.; Mohapatra, B. K.; Panda, D. J. Indian Chem. Soc. 1983, 60, 782-790.

[59]. Sanmartin, J.; Bermejo, M. R.; Deibe, A. M. G.; Maneiro, M.; Lage, C.; Filho, A. J. C. Polyhedron 2000, 19, 185-192.

[60]. Krzyminiewska, V. P.; Litkowska, H.; Paryzek, W. R. Monatsh. Chem. 1999, 130, 243-249.

[61]. Melnik, M.; Gyoryova, K.; Skorsepa, J.; Holloway, C. E. J. Coord. Chem. 1995, 35, 179-185.

[62]. British Pharmacopia, Her Majesty's Stationery Office, London, UK, 1998, p. 1040.

[63]. Cakir, S.; Bicer, E.; Odabasoglu, M.; Albayrak, C. J. Braz. Chem. Soc. 2005, 4, 711-717.

[64]. Koch, A. L. Clin. Microbiol. Rev. 2003, 16, 673-678

[65]. Chohan, Z. H.; Scozzafava, A.; Supran, C. T. J. Enzym Inhib. Med. Ch. 2003, 17, 261-269.

[66]. Chohan, Z. H.; Khan, K. M.; Supuran, C. T. Appl. Organomet. Chem. 2004, 18, 305-310. 